\title{
Wandering Diagnosis of Rheumatoid Arthritis in Lomé: Regarding a Case Secondary to Self-Medication based on Diclofenac for 11 Years
}

\section{Komi Dzidzonu Nemi ${ }^{1 *}$, Kodjo Agbeko Djagadou ${ }^{1}$, Abou Bakari Tchala ${ }^{1}$, Komi Edem Mossi ${ }^{1}$, Abdou Razak Moukaila ${ }^{1}$, Lihanimpo Djalogue $^{2}$, Toyi Tchamdja ${ }^{1}$, Abago Balaka ${ }^{1}$ and Mohaman Awalou Djibril $^{1}$}

${ }^{1}$ Department of Internal Medicine, Sylvanus Olympio Teaching Hospital, University of Lomé, Togo

${ }^{2}$ Department of Internal Medicine, Kara Teaching Hospital, University of Kara, Togo

*Corresponding Author: Komi Dzidzonu Nemi, Department of Internal Medicine, Sylvanus Olympio Teaching Hospital, Lomé, University of Lomé, Togo.
Received: September 30, 2020

Published: October 17, 2020

(C) All rights are reserved by Komi Dzidzonu Nemi., et al.

\begin{abstract}
This is a 45-year-old housewife who was referred by a paediatrician for an inability to lead an active life following polyarthralgia with bilateral deformity of the hand and bilateral knee swelling requiring self-medication based on diclofenac for 11 years without success. The examination on his admission noted a blood pressure $=151 / 120 \mathrm{mmHg}$, a deterioration of the general condition, the ulnar gale and a bilateral knee swelling. Additional tests have enabled to note: a biological inflammatory syndrome, microalbuminuria (165mg / 24h), one of bone mineralisation focal both wrists, a global toe interphalangeal distal joint spaces and metacarpophalangeal joint of the 3 rd ray right with erosion the adjacent metacarpal head, and multiple geodes of the carpal bones with bilateral carpal joint space pinching with tendency to form carpal block. There was also left atrial hypertrophy and apico-lateral subepicardial ischemia on the electrocardiogram and papillary excavation at the fundus. The diagnosis of rheumatoid arthritis was made based on a score greater than 6 from the American College of Rheumatology and the European League Against Rheumatism (2010). Management was carried out by corticosteroid therapy based on prednisone combined with functional rehabilitation of the joints. The frequency of rheumatoid arthritis would be underestimated in our country because of self-medication since the disease is sensitive to NSAIDs very accessible to the population, especially in illicit drug sales markets. We must make our populations more aware of the harmful effects of this practice.
\end{abstract}

Keywords: Rheumatoid Arthritis; Self-Medication; Lomé-Togo

\section{Introduction}

A systemic autoimmune disease, rheumatoid arthritis (RA) is the most common chronic inflammatory rheumatism in adults [13]. Its prevalence varies from one population to another [3-5]. It is a polyfactorial disorder arising from psychological, endocrine, environmental, genetic and immunological factors [1,5]. RA is a very heterogeneous disease whose evolution is extremely variable from one patient to another, ranging from mild forms that can heal com- pletely with little or no functional impairment, to severe forms with rapid joint destruction, source of a significant functional handicap and visceral damage that can be life-threatening [5]. Its diagnostic delay is still very important in our countries because of the minor forms very sensitive to anti-inflammatory drugs that can induce long remissions, without the definitive diagnosis being formally made and an adequate treatment and follow-up being undertaken [6]. We report a case treated for 11 years with self-medication based on diclofenac. 


\section{Case Observation}

This is a housewife of 45 years who consulted February 12, 2019 at the request of a Paediatrician for a bilateral shoulder pain, hand, wrist, elbow, knee and ankle with bilateral deformity of the hand and bilateral swelling of the knee. The onset of symptoms was 11 years ago marked by the occurrence of migratory arthralgia affecting wrists, the $2^{\text {nd }}$ and $3^{\text {rd }}$ metacarpal phalangeal and interphalangeal proximal, tarsometatarsal and metatarso-phalangeal as well as the ankle, having required self-medication based on diclofenac (street drug) $100 \mathrm{mg}$ twice daily with success. But the attack quickly became symmetrical with predominantly nocturnal pain accompanied by morning stiffness. The thrusts then followed one another and with each new thrust, other joints are affected, in this case the shoulders, the elbow, the knees and the lumbar spine. The diclofenac was continued especially during relapses until the appearance of deformities of the hand. It was in the face of the impossibility of leading an active life that his family took him for consultation with a paediatrician who referred him to the Sylvanus OLYMPIO University Hospital in Lomé for better care. In her history, she was not hypertensive or diabetic. There was also no family concept of arthritis rheumatoid. But there was a notion of family hypertension. The examination on admission had noted: An arterial tension $=150 / 120 \mathrm{mmHg}$ in both arms, a temperature $=$ $37.5^{\circ} \mathrm{C}$, a Weight $=72 \mathrm{Kg}$ for a height of $1.65 \mathrm{~m}$, an alteration of the general condition, an ulnar deviation fingers and flexion fixation of the metacarpophalangeal joints. The rest of the examination including the examination of the cardiovascular, respiratory, urogenital, gastrointestinal, spleno-ganglionnaire and nerve systems was normal. The additional examinations made it possible to note: Blood count: Hypochromia and microcytosis isolated, Blood sedimentation rate: $33 \mathrm{~mm} / \mathrm{h}$, Urea $=0.21 \mathrm{~g} / \mathrm{l}$, Creatinine $=9 \mathrm{mg} / \mathrm{l}$, Glycemia $=0.74 \mathrm{~g} / \mathrm{l}$, Total cholerol $=1.30 \mathrm{~g} / \mathrm{l} ;$ HDL-cholerol $=0.45 \mathrm{~g} / \mathrm{l}$; LDL- Cholesterol $=0.66 \mathrm{~g} / \mathrm{l}$; Triglycerides $=0.97 \mathrm{~g} / \mathrm{l}$, Calcemia $=94$ $\mathrm{g} / \mathrm{l}$; Magnesemia $=20 \mathrm{mg} / \mathrm{l}, 24$ hour proteinuria $=165 \mathrm{mg} / 24 \mathrm{~h}, \mathrm{Na}$ ${ }^{+}=136 \mathrm{mmol} / \mathrm{l} ; \mathrm{K}^{+}=3.5 \mathrm{mmol} / \mathrm{l} ; \mathrm{Cl}^{-}=94 \mathrm{mmol} / \mathrm{L}$, Backgrounds eye: AVB and excavation papillary, ECG: Left atrial hypertrophy and apico-subepicardial ischemia, Focal bone demineralization of both wrists, global pinching of the distal interphalangeal and metacarpophalangeal joint spaces of the $3^{\text {rd }}$ right ray with erosion of the adjacent metacarpal head, multiple geodes of the carpal bones with pinching of the carpal joint spaces bilateral with a tendency to form carpal block, osteophyte beginning at the left posterior superior patellar, enlarged tibial spines on the left, absence of anomaly of the joint spaces, X-ray of the shoulders: Focal demineralization of the humeral heads, osteophytic draft of bilateral acromioclavicular joint edges. Oeso-gastroduodenal fibroscopy in search of chronic gastritis secondary to chronic intake of Diclofenac was not honored by the patient, as were rheumatoid factor and anti CCP2 antibodies. The diagnosis of rheumatoid arthritis was made on the basis of at least 4 criteria of the ACR (1987):
- Arthritis of the joints of the hand

- Symmetric arthritis

- Arthritis of more than three joints

- Subcutaneous nodosity

- Bone demineralization of both wrists with erosion of adjacent metacarpal head.

\section{And with a score above 6 from ACR/EULAR (2010):}

- Affection of more than 10 joints (5 points)

- Duration of synovitis longer than 6 weeks (1 point)

- Increased blood sedimentation rate (1 point).

Management was performed by corticosteroid therapy based on prednisone $15 \mathrm{mg}$ per day, with gradual reduction of the dose every 15 days until a minimum effective dose of $5 \mathrm{mg}$, associated to a functional rehabilitation of the joints. However, the patient was lost to follow-up so that the basic treatment with Methotrexate was not instituted. Hypertension was treated with perindopril (10 mg per day).

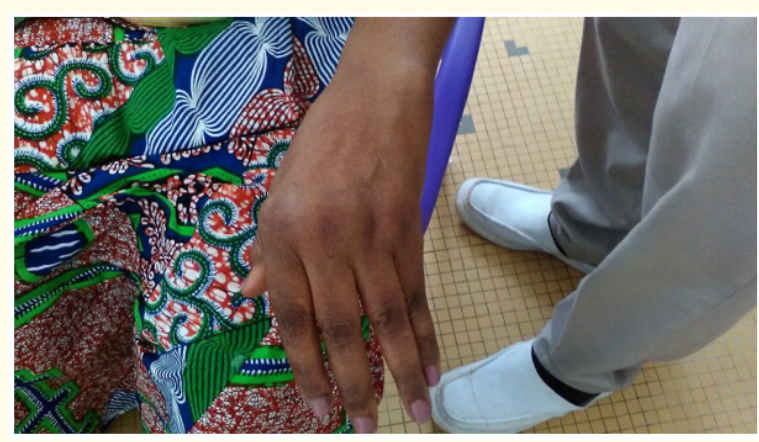

Figure 1: The ulnar gale.

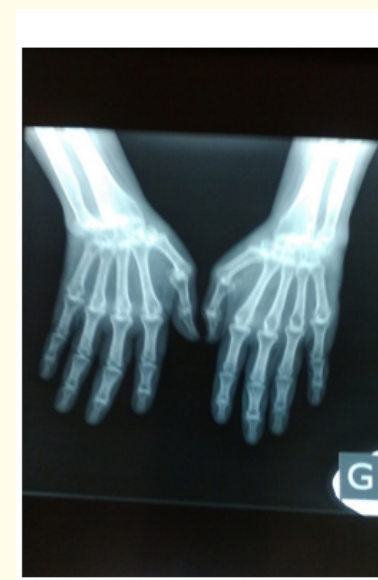

Figure 2

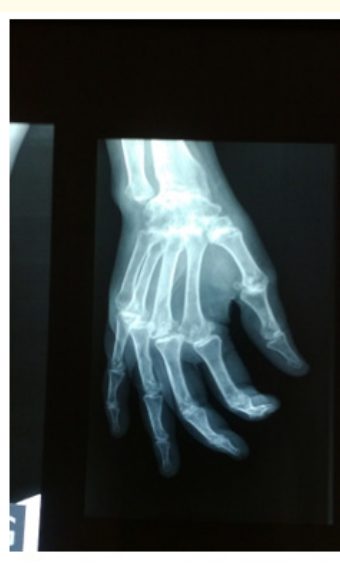

Figure 3
Figure 2 and 3: Focal bone demineralization of both wrists, global pinching of the distal interphalangeal and metacarpophalangeal joint spaces, multiple geodes of the carpal bones on the X-ray of both hands. 


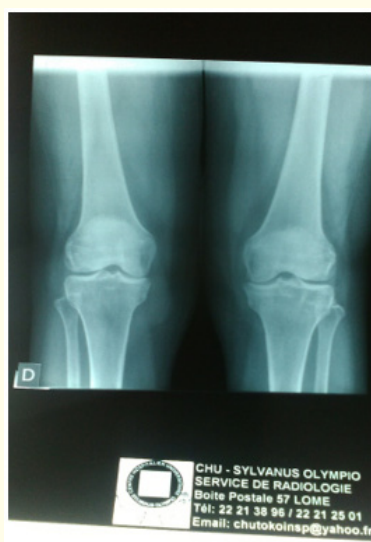

Figure 4

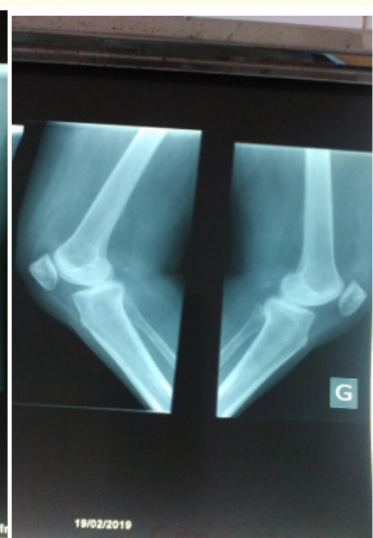

Figure 5
Figure 4 and 5: Osteophyte beginning at the left posterior superior patellar, enlarged tibial spines on the left, absence of anomaly of the joint spaces on the X-ray of both knees.

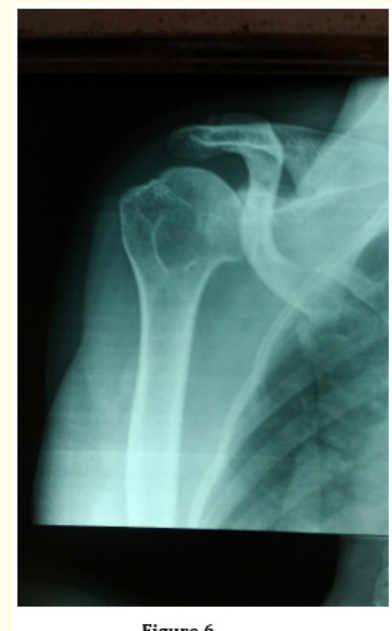

Figure 6

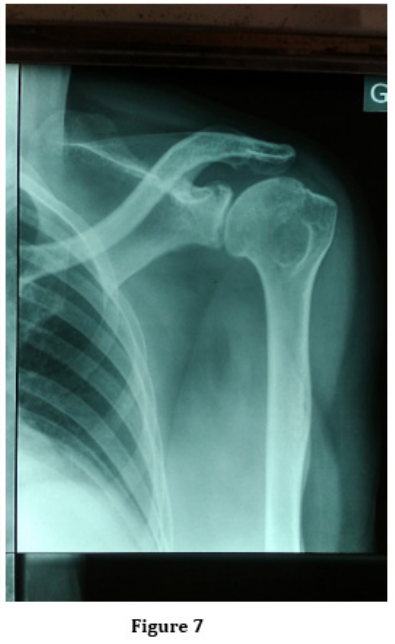

Figure 7
Figure 6 and 7: X-ray of the shoulders: Focal demineralization of the humeral heads, osteophytic draft of bilateral acromioclavicular joint edges.

\section{Discussion}

The frequency of RA worldwide varies from region to region but remains low ranging from $0.3 \%$ to $3.3 \%$ [5-11]. In fact, at the Sylvanus Olympio University Hospital in Lomé, its frequency was estimated at $0.3 \%$ in rheumatology over a 25-year period from 1990 to 2015 , i.e. around 4 cases per year [7]. This frequency of RA in our countries would certainly be underestimated since many patients indulge in traditional medicine and self-medication. In reality, the initial approach of populations in sub-Saharan African countries when faced with the first signs and symptoms of a disease is selfmedication [12]. The reasons given are many including the relief of symptoms before seeking more appropriate care, the geographic and financial inaccessibility of health centres [12]. The rate of selfmedication by analgesics and anti-inflammatory drugs would be the highest among the different therapeutic classes [13,14]. Added to this is the source of supply of these drugs, which is dominated by the illicit drug sales markets, no doubt because of their low price [15]. This is the case with our patient who adopted self-medication with diclofenac purchased from street drug dealers for 11 years and who was admitted only in the event of disability. Long delays in consultation were observed in series $[7,9,16,17]$, but they did not reach 11 years as in our patient. In addition, no study to our knowledge has reported self-medication for 11 years. The female predominance of RA is known $[1,3,4,7,9,10]$. Our patient was 45 years old, thus confirming the data in the literature according to which the age of predilection for the disease is between 30 and 60 years [7]. The chronology, site, symmetry and bilaterality of the articular involvement in our patient are typical. However, the predominance of joint sites varied from study to study. In a Togolese [7] and Congolese [19] series, the topography of the lesions was dominated by the involvement of the proximal interphalangeal joints of the hands. On the other hand, a predominance of the involvement of the wrist is reported in a Burkinabé [9] and Beninese [10] series. The ulnar gale was the major deformity in our patient, according to the data in the literature $[5,7,10,17]$. Complications of chronic intake of diclofenac including kidney damages (renal failure), livers (hypertransaminasemia) and hematologic (agranulocytosis, thrombocytopenia) were not observed in our patient. Gastrointestinal disturbances were not also observed in her due to lack of work-up. However, left atrial hypertrophy, sub-epicardial ischemia and microalbuminuria were the cardiac and renal damage found in her. But it was difficult for us to relate these lesions to RA alone since the patient was hypertensive but unknown, arterial hypertension (HTA) can also cause these complications. Regarding the type of arterial hypertension in our patient, it would probably be essential arterial hypertension since she had risk factors such as obesity, sedentary lifestyle, and familial hypertension. But this essential hypertension would be maintained by the chronic intake of diclofenac. The initial management of the PR was performed by prednisone as in most series $[7,10,16,19,20]$, but the patient was lost to view. 


\section{Conclusion}

The frequency of rheumatoid arthritis would be underestimated in our country. Some patients with the disease would self-medicate since RA is especially susceptible at the onset to nonsteroidal antiinflammatory drugs widely available in drug black markets and at lower cost. We must make our populations more aware not only of the harmful effects of self-medication, but also of the dangers of using street drugs. Promotion of lower cost essential generic drugs and health insurance for all should also be encouraged.

\section{Conflicts of Interest}

None.

\section{Bibliography}

1. Mac Gregor AJ and Silman A. "Rheumatoid arthritis: classification and epidemiology". In: Hochberg MC, Silman A, Slomen JS, eds. Rheumatology. London: Mosby (2003): 757-763.

2. Lee DM and Weinblatt ME. "Rheumatoid arthritis". Lancet 358 (2001): 903-911.

3. Mijiyawa M. "Aspects épidémiologiques et sémiologiques de la polyarthrite rhumatoïde dans le tiers monde". Revue du Rhumatisme 62.2 (1995): 127-132.

4. Jeandel P., et al. "Rhumatologie en Afrique noire: certitudes, perspectives et inconnues". Medecine d'Afrique Noire 38.1 (1991): 53-56.

5. Combe B. "Polyarthrite rhumatoïde: clinique et diagnostic". Encycl Méd Chir, Elsevier, Paris, Appareil locomoteur14220-A-10 (2006): 1-15.

6. Ka M M., et al. "La problématique des Maladies Auto-immunes en Afrique”. RAFMI 4.1-1 (2017): 7-8.

7. Kakpovi K., et al. "Profil de la polyarthrite rhumatoïde en consultation rhumatologique à Lomé (Togo)”. European Scientific Journal 13.15 (2017): 125-132.

8. Alamanos Y., et al. "Incidence and prevalence of rheumatoid arthritis based on the 1987 American College of Rheumatology criteria: asystematic review". Arthritis and Rheumatology 36 (2006): 182-188.

9. Ouédraogo DD., et al. "Rheumatoid arthritis in Burkina Faso: clinical and serological profiles". Clinical Rheumatology 30 (2011): 1617-1621.

10. Avimadjé M., et al. "La polyarthrite rhumatoïde au CNHU de Cotonou”. Le Bénin Médical 57.42/43 (2009): 55-57.
11. Solomon L., et al. "Rheumatoid arthritis in an urban South African Negro population". Annals of the Rheumatic Diseases 34 (1975): 128-135.

12. Etame Loe G., et al. "Evaluation de l'automédication par les antalgiques chez l'adulte: cas des clients des pharmacies d'officine de Douala, Cameroun". The International Journal of Biological and Chemical Sciences 11.4 (2017): 1461-1470.

13. Kouakou KE. "Description du profil des acheteurs des médicaments de la rue au marché Roxy d'Adjamé. Mémoire de santé publique". INFAS (2007): 74.

14. Saoudogo H. "Médicaments vendus sur le marché informel à Ouagadougou (Burkina Faso)". Thèse de Pharmacie (2003): 152.

15. Angbo-Effi KO., et al. "Facteurs déterminant la consommation des médicaments de la rue en milieu urbain". Santé Publique 23.6 (2011): 455-464.

16. Malemba JJ., et al. "The epidemiology of rheumatoid arthritis in Kinshasa, Democratic Republic of Congo.a populationbased study". Rheumatology 51 (2012): 1644 - 1647.

17. Eti E., et al. "Contribution of the study of the rheumatoid arthritis in Ivorian Hospitals. About 90 cases". Rev Int Sciences Méd 2 (2000): 71-78.

18. Atouf 0., et al. "Polymorphisme HLA et polyarthrite rhumatoïde précoce dans la population marocaine". Revue du Rhumatisme 75 (2008): 824 -830.

19. Bileckot R and Malonga AC. "La polyarthrite rhumatoïde en milieu hospitalier au Congo Brazaville à propos de 36 cas". Revue du Rhumatisme 65 (1998): 333-337.

20. Roux H. "Polyarthrite rhumatoïde en Afrique subsaharienne". Revue du Rhumatisme 69 (2002): 797-800.

\section{Assets from publication with us}

- Prompt Acknowledgement after receiving the article

- Thorough Double blinded peer review

- Rapid Publication

- Issue of Publication Certificate

- High visibility of your Published work

Website: www.actascientific.com/

Submit Article: www.actascientific.com/submission.php

Email us: editor@actascientific.com

Contact us: +919182824667 